\title{
A Critical Assessment of Poverty Reducing Employment Strategies for Africa
}

\author{
Wilfred Awung Ndongko ${ }^{1}$ Ismaila $\mathrm{Amadu}^{2}$ \\ 1.Cameroon Academy of Sciences, Cameroon \\ 2.National Committee for the Development of Technologies, Ministry of Scientific of Research and Innovation, \\ Cameroon \\ P.O.BOX 1457 Yaounde, Cameroon
}

\begin{abstract}
This paper critically assessed some employment poverty reducing strategies put in place in Africa. From the assessment, it was realized that the strategies did not adequately contribute to generate decent and well remunerating jobs that could substantially curb poverty. As a result of this limited success of the strategies was partly attributed to limited public investments, inadequate planning and execution of development projects, dreadful mismanagement and poor allocation of resources, etc. Consequently, Africa habours about half of the world's poor, vulnerable and underprivileged population. Thus, in an effort to reverse the situation, it is recommended that African countries should: provide professional and scientific training and education which is relevant to the needs of their economies; put in place a range of incentives which would attract foreign investments that will transform their primary and agricultural products locally; promote the intensive use of labour in implementing sustainable projects; and increase their investment in Science, Technology and Innovation.
\end{abstract}

Keywords: Employment; Decent Jobs; Strategies; Poverty Alleviation; African Economies

DOI: $10.7176 / \mathrm{JESD} / 12-3-01$

Publication date: February $28^{\text {th }} 2021$

\section{Introduction}

Poverty refers to the incapacity of an individual to satisfy his/her basic needs like nutrition, healthcare, transportation, clothing, education, housing, etc, as well as those of the people (family) depending on him/her for their livelihood due to extremely limited or lack of material and financial resources. Poverty, therefore, could be lack of monetary or non-monetary means to live a decent life. It is monetary when the daily income of an individual is below USD 1.9 (the so called poverty line) and non monetary when an individual does not have physical assets like cars, houses, and land that could be transformed into liquid assets.

According to the World Bank (2018), about 10 percent of the world's population lived on less than USD 1.9 a day in 2015 of which more than one fifth lives in developing and non-industrialized economies, constituting about 1.2 billion people. For example, in Cameroon, the percentage of the population living in poverty is 39.9 per cent. Although, the percentage of the poor has decreased from about 53 per cent in 1996 to approximately 40 per cent in 2001 (DSCE, 2009), its proportion is still very relatively high compared to Central Asia where the proportion of the population living in poverty is about 3 per cent.

The poor population is mainly concentrated in the North and Far North Regions of the country. These two regions harbor $56 \%$ of the poor in Cameroon (World Bank, 2018). The alarming level of poverty in the country is partly accounted for by high unemployment particularly among the youths; who constitute more than 50 per cent of the country's population.

In Cameroon, the unemployment rate stood at 4.24 per cent in 2017 ; and that among the youths was estimated at 8.94 per cent. On average, across regions, the world over, youth unemployment is about 2 to 3 times higher than the national unemployment rate (World Bank, 2018). Youth unemployment is usually concentrated among the less educated, but in efficient labour markets the unemployment rate is high even among the educated (Jean and Erwin, 2007). Moreover, in Africa, women as a group have remained over presented among the unemployed and have often been in marginal and poorly remunerated activities (ILO, 1999). Although the financial situation of women is improving, it is not yet satisfactory and worse than that of men.

In Cameroon, in particular and developing countries in general, employment is low because their economies are weak, non-industrialized and largely dependent on the sales of agricultural and primary products as well as raw materials, with high fluctuating prices fixed by the buyers on the international market. For this reason, generating employment and increasing the incomes of people is a dream yet to come true. As a result, more than half of the extremely poor population lives in Sub-Saharan Africa.

Worse still, the number of the poor people in the African region increased by 9 million, with 413 million people living on less than USD 1.9 a day in 2015, more than all the other regions combined. If the trend continues, by 2030, nearly 9 out of 10 extreme poor will be in Sub-Saharan Africa. The majority of the poor lives in rural areas and are poorly educated, employed in the agricultural sector, and are under 18 years of age (World Bank, 2018). 
If this phenomenon is not addressed appropriately, more Africans will be trapped in poverty for many decades to come. It is on the basis of the conviction that poverty can be reduced if people have decent and productive jobs, that a new target was added under MDG 1 in 2006: achieving full and productive employment and decent work for all, including women and young people. It was in this light that ILO (2008) argued that "Nothing is more fundamental to poverty reduction than employment." It further argued vigorously for "decent employment", that is, work that offers people a good income, security, flexibility, and protection.

Employment is not only a source of income and securing livelihood and access to social services, but is equally necessary for an individual's dignity, self-esteem, and an important element for social recognition and inclusion (ILO, 2008). ILO divides employment into four categories: (i) employees who are paid wages or salaries based on an explicit or implicit contract; (ii) employers who are self-employed and have engaged one or more employees; (iii) own-account workers, alone or with one or more partners, are self-employed and have not engaged employees; and (iv) contributing family workers are employed on an informal basis in an establishment operated by a relative living in the same household.

Basically, the relationship between poverty and employment lies in the extent to which income generated from employment permits workers and their dependants to have access to the goods and services necessary to meet their basic needs and improve their livelihoods.

To this extent, poverty irrespective of its type depends on the level of income which in turn determines the purchasing power of people. With a daily income of USD 40, for example, a person can afford more material goods, have access to basic services like education, transportation, telephone, internet, healthcare, etc and improve his/her well-being. In fact, the earnings or income of people are a determinant factor in considering them as poor or not.

\section{Reducing Poverty Through Employment: Conceptual Analysis}

Poverty reduction requires the creation of regular and well paid jobs in the labour market. It also calls for the general enhancement of the productive ability of the "working poor" in the self-employment and home-based sectors. It implies the creation of the necessary and minimum conditions for improved incomes, working conditions and the protection of the vulnerable working population (ILO, 2008). According to Jean and Erwin (2007), employment is not only the main source of income, it also enhances other dimensions of the well-being of people, including skills, physical abilities, and self-respect. Reducing poverty through employment requires three major thrusts: (i) generate employment, (ii) increase employability, and (iii) make the labor markets more efficient, flexible and mobile.

\subsection{Generating Employment}

Generating employment requires regulatory policies that facilitate the creation and growth of private, foreign and public enterprises that would employ people, produce, sell their products and remunerate their employees well.

\subsection{Increasing Employability}

The provision of social services particularly education and training, adequate basic healthcare, family planning and nutrition, both to improve living conditions and increase the capacity of the poor to respond to income earning opportunities arising from economic growth and development. This does not only enable people to work and earn decent income but also prevents poverty caused by sickness, especially when health insurance is not available or in cases where a significant proportion of a population is not covered. However, these social services have to be affordable by and accessible to the poor.

\subsection{Make the Labour Market More Efficient}

This could be done by facilitating the flow information on employment opportunities, making it more accessible to job seekers, easing the mobility of workers, limiting frictions in employment procedures, etc. The poor can escape poverty if they are employed, paid a substantial wage that would enable them to live decently, have social protection, and increased productivity (for those self employed so as to make more benefits). In fact, without a reasonable remuneration, generating more jobs would not reduce poverty, but would rather trap the employed in poverty.

Its is in this regard that ILO (2008) estimated that there are as many as 487 million workers living under the internationally one dollar a day poverty line. The large majority of these people are in the informal sector. It is therefore imperative to create additional well remunerating formal jobs in order to get many more people out of the informal sector and reduce poverty.

East Asia and the Pacific, Europe and Central Asia have managed to reduce poverty to below 3 per cent of their population by making among other things, the creation of well paid jobs for their citizens a priority. In 2015 , 736 million people lived on less than USD 1.90 a day, down from 1.85 billion in 1990 (IMF, 2018). As a result of the progress made in industrialization of the regions that led to the creation of millions of additional jobs for people 
and a subsequent increase in income, government revenue and the provision of social services like healthcare, education and housing. Moreover, for those who have been able to move out of poverty, progress is often temporary: economic shocks, food insecurity and climate change have threatened to rob them of their hard-won gains and force them back into poverty (World Bank, 2018).

\subsection{Ensuring Efficient Utilization of Lobour}

Poverty in developing countries is principally linked to the underutilization of labour, whether in the form of open unemployment or massive underemployment as well as low wages. Poverty can be linked to unemployment, especially in urban areas which, in the last three decades, have expanded to accommodate large influxes of jobseekers. Most of the urban poor are either unemployed or continually face irregular job access and precarious working conditions.

However, the vulnerability of the poor is largely due to underemployment and low returns on labour rather than unemployment, since the poor generally undertake any available economic activity, regardless of the remuneration and working conditions, in order to survive. Thus, the majority of the poor in the world are "working poor", in the rural and urban informal sectors, who work long hours and combine multiple activities but are still unable to earn enough to satisfy their basic needs (ILO, 2008). For example, in 2006, there were 1.3 billion people who worked but were still unable to lift themselves and their families above the USD 1.9 a day poverty line.

China using employment, among others things, made the single largest contribution to global poverty reduction in the last three decades. This is partly because its private sector has been the fastest growing segment of the economy, growing at 20 per cent per year for the last 25 years, which is more than double the economy's average. Since 1992, the private sector in China created three-quarters of all new jobs. This clearly demonstrates the critical role growth and employment played in reducing poverty in the country.

In order to make employment work effectively in reducing poverty, the challenge is not only to create jobs, but also to create decent and better jobs, that is, those that offer adequate pay and offer sufficient social protection. The informal sector has frequently failed to play this role.

In many parts of the world, being employed informally constitutes the norm, not the exception. Informal employment refers to jobs or activities in the production and sales of legal goods and services which are not regulated or protected by laws of the state. On a worldwide average, more than half of all jobs in the nonagricultural sector can be considered informal. In some regions, including Sub-Saharan Africa and South Asia, this rate reaches at least 80 per cent.

Clearly, informal employment constitutes a large and growing segment of the world's labour markets. Its persistence limits the effectiveness of employment as a tool for poverty reduction and has serious repercussions on the social and economic development of the various countries.

This also implies an inefficient use of available human resources as informal jobs are believed to be associated with lower efficiency and productivity. For individuals, being informally employed often means being locked in low-paid, high-risk and precarious activities - a situation particularly challenging in the developing world considering the fact that labour is by far the most important productive asset of the world's poor. Indeed, informal jobs put workers in a vicious circle of low pay, high risks and limited mobility.

\section{An Assessment of Some Employment Poverty Reducing Strategies}

In order to curb poverty through employment, countries have proceeded differently. Some examples of poverty reducing employment strategies or mechanisms to fight against poverty include:

\subsection{Promoting Broad Base Economic Growth}

The World Development Report (1990) demonstrated that poverty has declined in some countries because the broad base economic growth was enhanced. When there is economic growth stimulated from the base, abundant unskilled labor could be used more intensively and generate more income for the poor who are usually the ones employed at the base, thus reducing poverty.

Promoting private sector development is primordial in fighting against poverty because it recruits a lot and the State cannot employ everyone. It was introduced in Indonesia and Thailand in the 90s. However, such growth has to be "pro-poor". Otherwise, there could be growth without any significant impact on poverty reduction. In this case, economic growth has to be very high, sustainable and inclusive.

\subsection{Improving the Business Environment}

Given the increasing mobility of enterprises and the important role of the private sector and FDI in creating employment, increasing incomes and boosting government revenues, various countries are putting in place new strategies and improving old ones to attract firms in search for optimum location sites.

To do this, countries have put in place incentives such as farm to market roads, rural electrification, irrigation schemes, connections to telephone and internet, hospitals, schools, etc. that could enable and ease investments in 
the rural and urban areas and eventually increase employment, and the creation and distribution of wealth.

Although this strategy has contributed in reducing poverty, many poor might not fully benefit from the opportunities it has provided if the population is sick and it is largely illiterates with very limited and/or lack of skills. This implies that investments geared towards improving the provision of social services, notably healthcare, education, training and housing should always accompany such strategies.

\subsection{Promoting Sustainable Rural Industrialization}

This is measured using indicators such as the extent to which it contributes to job creation, income generation, and the preservation of the environment, as well as the impact on productivity through the generation of forward and backward linkages within the rural space economy, and lasting impact and survival of the industries to promote rural development (Mashini and Villiers, 2001). It was introduced in Lesotho through the implementation of cost effective labour for industrial companies.

The government of Lesotho created Handicraft Centers in rural areas to train people in knitting, sewing, candle making, soap making, and pottery. However, such Centers were frequently closed because of poor commitments of funds from the government, limited external funds, the absence of a viable domestic market and a poor competitive advantage in the international market.

Moreover, poor governance and dreadful mismanagement of economic resources coupled with government policies that favoured urban industries, in terms of investor incentives like the provision of development infrastructure and services, contributed in compromising the efforts of the government in harnessing and enhancing rural industrialization (Mashini and Villiers, 2001).

Rural industries have remained poorly resourced, which in no doubt here increased their production cost, reduced their competitiveness and profit margin. For these reasons, their shutdown in a highly competitive globalized world is certain. This resulted in massive layoffs of employees, salary/wage slashes, fall in incomes and an increase in poverty in the rural areas. This might extend to the urban areas if the rural industries had direct or indirect links with industries in the urban areas.

\subsection{Investing in High Impact Projects}

Projects like the construction of hydroelectricity dams to generate power, bridges, railways, roads, etc do not only create employment during their execution but also facilitate the implantation of industries that depend on them for production and the evacuation of their produce (ILO, 2000). A huge number of such projects have been entirely or jointly financed by the host countries and/or with the World Bank, International Monetary Fund (IMF), African Development Bank (AfDB), International Development Bank (IDB), the European Union (EU), etc. on the African continent.

This policy is to ease business, attract more investors so that employment is created, the poor employed, revenues increased and poverty reduced. However, most of these projects are executed by foreign companies that unfortunately give most of the highly remunerated and white collar jobs to foreign workers whom they consider to be more skillful; while local unskilled labor is used with relatively very low remuneration.

\subsection{Promoting Massive investments in All the Key Sectors of the Economy}

Through government-led massive poverty alleviation and development programmes, the rural poverty-stricken population was significantly reduced in China in the last decades. This was realized particularly through the significant improvement of infrastructure in impoverished areas, and the constantly rising basic public service.

As a result, China reduced the percentage of its population living in extreme poverty from 88 per cent in 1981 to 1.8 per cent in 2013 . To this effect, China has contributed to over 70 per cent of the poverty reduced across the world, and taken the lead to reach the United Nations Millennium Development Goals (UN MDGs). This has made it the country with the most people lifted out of poverty in the world (Tan, 2018)

At the end of 2012, there were 98.99 million people living under the current poverty line. By the end of 2017, the total poverty-stricken population stood at 30.46 million, with more than 66 million people being lifted out of poverty over five years (Tan, 2018).

This incredible success in the fight against poverty by the Chinese government was as a result of massive investments in such sectors as industry, health, agriculture, education, social services, commerce, energy, technological development and innovation. All these investments propelled the Chinese economy to 20 per cent growth rates for about two decades. This boosted production, increased exports, increased employment and incomes.

As a result, poverty has been reduced in a spectacular manner in China in the past decades. It is worth noting that this success was possible because:

First, the Chinese society was involved in the identification of the poor and the elaboration of the strategies;

Second, clear goals to be attained were set and the people responsible and accountable for their realization in each locality were appointed; 
Third, strict supervision and assessment measures were put in place to avoid corruption, misallocation of resources, and delays in the execution of projects;

Fourth, resources were mobilized and made available to accomplish the task.

\section{Recommendations}

During the last two decades, countries particularly in Central Europe, Asia, and Latin America have made significant progress in creating employment, raising the revenues of their citizens, and reducing poverty. In Africa, limited progress has been made in some countries like Cameroon, South Africa, Zambia, Kenya, Seychelles and Rwanda.

However, in general, poverty has not reduced in Africa as earlier indicated. Worse still, unemployment is rising, with about 12 million new job seekers coming into the labour market every year in the continent (AfDB, 2018). This has created a serious threat to peace, security and social and political stability of Africa as well as in other continents in the form of terrorism, organized cross border crimes, human trafficking, etc. For this reason, it is recommended that African countries should:

First, provide professional and scientific training and education which is relevant to the needs of their economies. This would enable their graduates to easily obtain employment that is well remunerated because they are qualified for the available jobs. Also, equipped with professional skills, the graduates can set up their own businesses, enterprises, innovation hubs, etc that would not only employ them, but also enable to earn decent incomes as well as employ others;

Second, put in place a range of incentives which would attract foreign investments that will transform their primary and agricultural products instead of exporting them to multinational companies offshore (United Nations Economic Commission, 2011). By transforming these raw materials locally, more jobs and wealth will be created on the continent. To this extent, Africa would properly fight against poverty. It is worth noting that poverty cannot be reduced by selling agricultural and primary products under the condition of fluctuating prices set by buyers. It is through industrial production that poverty can be effectively fought and eradicated;

Third, promote the intensive use of labour in implementing sustainable projects. Nonetheless, control measures should be put in place to ensure that the working conditions in enterprises are good, so as to limit frequent accidents at work and sickness due to poor conditions. When employees are working in poor conditions without any social protection, they might end up or remain poor if they fall sick and spend all their meager earnings treating themselves. Thus, social protection like health and life insurance should be made available to employees to avoid their falling back into poverty due to ill health or accidents at the work place;

Fourth, African countries could use the Chinese model and adapt it to their respective contexts. However, this model requires enormous resources which most African countries lack. In this regard, it should be pointed out that the Chinese government spent over 1000 billion Yuan between 2012 and 2017 in the fight against poverty. Therefore, in order to successfully adopt the Chinese model: bottom up policy crafting should be implemented, include urban poor, limit mismanagement, improve transparency and accountability, and ensure the availability and sustainability of financial resources; and,

Fifth, increase their investment in Science, Technology and Innovation (STI). Investing in capital (human and physical) has been and is still critical for economic growth, employment and poverty reduction, as well as economic development (Wangue and Hobbs, 2001). But in recent years, it is STI enhanced by R\&D that are shaping the world, increasing production, improving sales and competitiveness, generating more decent jobs, creating more wealth and improving living standards (AfDB, 2018). Investing in STI should be a top priority for African countries given the importance of the former in industrial and economic transformation, for generation of more well remunerated jobs, and eventually the fight against poverty.

\section{Conclusion}

It should be noted that in general, there has been good progress on reducing poverty over the past decades in the world. Despite the progress, the number of people living in extreme poverty globally remains unacceptably high, especially in the less developed economies (AfDB, 2018). For example, in Cameroon, the percentage of the population living in poverty is above 30 per cent. This clearly shows that a lot has to be done so as to reduce poverty even to 3 per cent of the countries population.

The alarming level of poverty in the country has been quite stable for the past two decades. This is partly accounted for by the long lasting devastating consequences resulting from the implementation of the Structural Adjustment Programmes (SAPs) in the late 1980s and early 1990s, which compelled the government of Cameroon to significantly squeeze its investments sectors like education, health, industry, transport, infrastructure, agriculture, etc that constitute the engine of growth, employment, and economic development.

Moreover, 70 per cent salary cuts drastically reduced the purchasing of Cameroonians to a barely minimum required to survive and not to live a decent life. Although the SAPs have helped some African countries to resume economic growth, they have neither increased employment nor reduce poverty in many other African countries 
(Ndongko, 2000). Therefore, there is no doubt, this has put many people in poverty and they have been strapped in it for decades.

This situation further weakened the countries industries and devastated their economies. The weakening of $t$ industries limits a country's capability and capacity to transform its agricultural and unprocessed raw materials locally, and instead stimulate their sales to foreign companies overseas. In such a situation, less decent and well remunerated jobs will be created, unemployment will remain high, and poverty will persist as presently witnessed in Africa.

In recent years, it is the 2008 economic crisis and the fall in the prices of crude oil, agricultural and raw materials that have been slowing growth and adversely affecting employment and reducing incomes and purchasing power in Africa.

Additionally, frequent floods, droughts, increased temperatures, strong and destructive winds that have been amplified by climate change are equally hampering agriculture in Africa and the world at large, thereby adversely affecting food production. Consequently, more people are exposed to hunger and malnutrition, climatic migrants increasing as exemplified by the large numbers leaving the continent, particularly through the coasts of Libya, and Morocco for Europe and the rest of the world for a better life.

Moreover, socio political crisis and the high level of insecurity constitute a great threat to business and wealth creation in Cameroon in particular and Africa general. It is in this regard that the economic growth rates in the near future might not be high, sustained and inclusive in developing countries, including Cameroon to enhance poverty reduction so as to reach the target of ending extreme poverty by 2030 (World Bank, 2018).

So, Cameroon and other African countries should step up their efforts to increase decent employment, improve social security and services, in order to raise incomes and considerably reduce poverty in the continent. At the same time, it does not suffice merely to generate more jobs and improve income opportunities. The poor must equally have the capacity and the ability to develop, protect and sustain their livelihood. This implies effective access to and control over resources and bargaining power to compete with other interest groups for a better share of the national resources and benefits; and participation in the political processes which determines resource distribution in a country.

\section{References}

African Development Bank (2018). African Economic Outlook. 2018 Edition.

Aneel. K., (2011). Reducing Poverty through Employment. Innovations, Volume 6, number 2.

Document Stratégique pour la Croissance et l'Emploi. (2009). Yaoundé-Cameroun.

Economic Commission for Africa (2011). Industrial Policies for the Structural Transformation of African Economies: Options and Best Practices. ECA Research Work on Policies, No 2. Addis Ababa

International Labour Organization (1999). Jobs for Africa-Poverty Reducing Employment Strategies for SubSaharan Africa (JFA-PRESSA): An Overview of the Background, Objectives, Achievements and Future Prospects.

International Labour Organization (2000). Etude sur les Investissements Pour l'Emploi Aptes à Réduire la Pauvreté (IPRE), Rapport Final.

International Labour Organization (2008). Excerpt from ILO International Training Centre. Module on Gender, Poverty and Employment.

International Monetary Fund (2018). World Economic Outlook: Cyclical Upswing, Structural Changes. Washington.

Jean, F., and Erwin, R, T. (2007). Youth Unemployment, Labour Market Transitions, and Scarring: Evidence from Bosnia and Herzegovina, 2001-04. World Bank Policy Research Working Paper 4183.

Mashini, IV and Villiers, G, D, T, D. (2001). Taking Up Arms in Africa's War on Poverty. Africa Insight. Vol 31, $\mathrm{N}^{\circ} 4$.

Ndongko, W, A. (2000). Investment-Led Growth Strategy for Employment Promotion in Africa: Lessons from the Jobs for Africa (JFA) Programme.

Samuel. F., Andy. M., Joseph-Pierre. T., Olive. S. K., Anaclet, D., and Romain. T. (2014). Growth, Poverty, and Inequality: The Case Study of Cameroon. World Institute for Development Economics Research. WIDER Working Paper 2014 / 154.

Tan. W. (2018). Chinese Approach to the Eradication of Poverty: Taking Targeted Measures to Lift People out of Poverty. A Speech at the Expert Panel on the Implementation of the Third UN Decade for the Eradication of Poverty (2018-2027). Addis Ababa, April 18, 2018.

Wangue, S, M., and Hobbs, G, T. (2001). Investment for Poverty-Reducing Employment (IPRE) Study: A Synthesis. Economic and Social Research Foundation (ESRF).

World Bank (1990). World Development Report: Poverty. Washington

www.sida.se/urban: Supplement to Sida's Policy for Urban Development. Fighting Poverty in an Urban World. https://knoema.com/infographics/voqacsf/poverty. 
https://www.worldbank.org/en/topic/poverty/overview.

https://www.worldbank.org/en/country/cameroon/overview.

https://www.statista.com/statistics/811928/youth-unemployment-rate-in-cameroon. 